\title{
A randomised double-blind, cross-over trial of 4-aminopyridine for downbeat nystagmus-effects on slowphase eye velocity, postural stability, locomotion and symptoms
}

\author{
Jens Claassen, ${ }^{1}$ Rainer Spiegel, ${ }^{1}$ Roger Kalla, ${ }_{1}^{1}$ Mary Faldon, ${ }^{2}$ Christopher Kennard, ${ }^{2}$ \\ Chotipat Danchaivijitr, ${ }^{2}$ Stanislaw Bardins, ${ }^{1}$ Nicole Rettinger, ${ }^{1}$ Erich Schneider, ${ }^{1}$ \\ Thomas Brandt, ${ }^{1}$ Klaus Jahn, ${ }^{1}$ Julian Teufel, ${ }^{1}$ Michael Strupp, ${ }^{1}$ Adolfo Bronstein ${ }^{2}$
}

\begin{abstract}
- Additional material is published online only. To view please visit the journal online (http://dx.doi.org/10.1136/ jnnp-2012-304736).

1 Department of Neurology and German Center for Vertigo and Balance Disorders (IFBLMU), University Hospital Munich, Campus Großhadern, Munich, Bavaria, Germany

${ }^{2}$ Division of Brain Sciences, Imperial College London, Charing Cross Hospital, London, UK
\end{abstract}

\section{Correspondence to} Professor Michael Strupp, FANA, Department of Neurology and German Center for Vertigo and Balance Disorders (IFBLMU), University Hospital Munich, Campus Großhadern, Marchioninistr 15 Munich, Bavaria 81377, Germany; michael.strupp@ med.uni-muenchen.de and Professor Adolfo M Bronstein, Division of Brain Sciences (Neuro-otology Unit), Imperial College London (Charing Cross Hospital), London W6 8RF, UK; a.bronstein@imperial.ac.uk

$\mathrm{JC}$ and RS contributed equally.

Received 7 December 2012 Revised 28 May 2013 Accepted 30 May 2013 Published Online First 29 June 2013

\section{SLinked}

- http://dx.doi.org/10.1136/ jnnp-2013-305191

To cite: Claassen J, Spiegel R, Kalla R, et al. J Neurol Neurosurg Psychiatry 2013;84:1392-1399.

\section{ABSTRACT}

Objective The effects of 4-aminopyridine (4-AP) on downbeat nystagmus (DBN) were analysed in terms of slow-phase velocity (SPV), stance, locomotion, visual acuity (VA), patient satisfaction and side effects using standardised questionnaires.

Methods Twenty-seven patients with DBN received $5 \mathrm{mg}$ 4-AP four times a day or placebo for 3 days and $10 \mathrm{mg}$ 4-AP four times a day or placebo for 4 days. Recordings were done before the first, $60 \mathrm{~min}$ after the first and $60 \mathrm{~min}$ after the last drug administration.

Results SPV decreased from $2.42 \mathrm{deg} / \mathrm{s}$ at baseline to $1.38 \mathrm{deg} / \mathrm{s}$ with $5 \mathrm{mg} 4-\mathrm{AP}$ and to $2.03 \mathrm{deg} / \mathrm{s}$ with $10 \mathrm{mg} 4-\mathrm{AP}$ ( $p<0.05$; post hoc: $5 \mathrm{mg} 4-\mathrm{AP}: \mathrm{p}=0.04$ ). The rate of responders was $57 \%$. Increasing age correlated with a 4-AP-related decrease in SPV $(p<0.05)$. Patients improved in the 'get-up-and-go test' with 4-AP ( $p<0.001$; post hoc: $5 \mathrm{mg}: p=0.025 ; 10 \mathrm{mg}$ : $p<0.001)$. Tandem-walk time (both $p<0.01$ ) and tandem-walk error (4-AP: $p=0.054$; placebo: $p=0.059$ ) improved under 4-AP and placebo. Posturography showed that some patients improved with the $5 \mathrm{mg}$ 4-AP dose, particularly older patients. Near VA increased from 0.59 at baseline to 0.66 with $5 \mathrm{mg} \mathrm{4-AP}$ $(p<0.05)$. Patients with idiopathic DBN had the greatest benefit from 4-AP. There were no differences between 4-AP and placebo regarding patient satisfaction and side effects.

Conclusions 4-AP reduced SPV of DBN, improved near VA and some locomotor parameters. 4-AP is a useful medication for DBN syndrome, older patients in particular benefit from the effects of $5 \mathrm{mg} 4$-AP on nystagmus and postural stability.

\section{INTRODUCTION}

Downbeat nystagmus (DBN) is the most frequent form of acquired nystagmus in the primary position. ${ }^{1}$ It impairs visual acuity (VA) as a result of vertical oscillopsia ${ }^{2-4}$ and is associated with postural instability. ${ }^{5} \mathrm{DBN}$ is most often caused by impaired cerebellar function, mainly of the flocculus, for example, due to cerebellar degeneration. ${ }^{37-9}$

In DBN the eyeballs drift slowly upwards followed by a downward correcting saccade. ${ }^{4}$ The upward drift may be due to impaired function of floccular Purkinje cells $(\mathrm{PCs})^{10}$ and their physiological asymmetry. ${ }^{11}$ Once damaged, the disruption of the system may disinhibit superior vestibular nucleus cells, resulting in spontaneous upward eye drift. ${ }^{12}$

Aminopyridines have been used in LambertEaton myasthenic syndrome and multiple sclerosis. $^{13-17}$ It is known that aminopyridines (4-aminopyridine (4-AP), 3,4 diaminopyridine) reduce the mean peak slowphase velocity of DBN, ${ }^{5} 10 \quad 18-20$ and 4-AP prevents attacks in episodic ataxia type 2 (EA 2$)^{2122}$ and improves interictal cerebellar ataxia ${ }^{23}$ and gait $^{24}$ in EA 2. Their effects on the attacks were also confirmed in an animal model of EA 2, the tottering mouse. ${ }^{25} 26$

So far, one explanation for its effects on DBN was that 4-AP augments the impaired physiological inhibitory influence on superior vestibular nuclei neurons by increasing the excitability of PCs. ${ }^{27}$ In the abovementioned animal model of EA 2 it was found that 4-AP facilitates synchrony of firing of the PCs and such action would also enhance the inhibitory influence. ${ }^{25}$

As several studies had already shown that 4-AP reduces the intensity of DBN, in the current placebo-controlled double-cross-over bi-centre trial we focused on its effects in two different dosages on slow-phase eye velocity, VA, postural stability, locomotion $^{28} 29$ and symptoms.

\section{METHODS}

Level of evidence

This cross-over study provides Class II evidence that 4-AP decreases slow-phase velocity (SPV) and improves the results of the get-up-and-go test in patients with DBN.

\section{Patients}

Twenty-seven patients with DBN were included; their clinical features are summarised in table 1. The patients were 23-78 years old (mean 64.85 \pm 12.01 years; aetiology: 21 idiopathic, six cerebellar degeneration). The mean duration of symptoms attributed to DBN was 8.48 years $( \pm 8.49$ range 1 40 years). As in previous studies, ${ }^{30}$ all patients underwent a complete clinical examination. In one case MRI imaging was not possible, but the aetiology was considered idiopathic because there were 
Table 1 Clinical characteristics of the patients with downbeat nystagmus (DBN), categorised by gender, age, neuro-ophthalmological findings, MRI findings, aetiology of downbeat nystagmus, disease duration since diagnosis and response to treatment

\begin{tabular}{|c|c|c|c|c|c|c|c|}
\hline Subj. & $\begin{array}{l}\text { Age, } \\
\text { sex }\end{array}$ & $\begin{array}{l}\text { Sequence of } \\
\text { treatment }\end{array}$ & Aetiology of DBN & $\begin{array}{l}\text { Duration of } \\
\text { DBN }\end{array}$ & MRI findings & $\begin{array}{l}\text { Neuro-ophthalmological findings (apart from } \\
\text { DBN) }\end{array}$ & $\begin{array}{l}\text { Response* } \\
(\%)\end{array}$ \\
\hline 1 & $70, \mathrm{~m}$ & 4-AP-placebo & Idiopathic & 16 & Normal & 3,6 & -152.91 \\
\hline 2 & $76, f$ & 4-AP_placebo & Idiopathic & 10 & Normal & $1,2,3$, left gaze hypermetric saccades & \\
\hline 3 & $69, \mathrm{~m}$ & Placebo-4-AP & $\begin{array}{l}\text { Secondary } \\
\text { (degeneration) }\end{array}$ & 4 & Cerebellar atrophy & $1,2,4,3$ & \\
\hline 4 & $65, \mathrm{~m}$ & 4-AP_placebo & Idiopathic & 2 & Normal & $1,2,3,6$ & 48.06 \\
\hline 5 & $78, f$ & 4-AP-placebo & Idiopathic & 8 & Relatively small flocculus & $1,2,3,5,6$, horizontal hypermetric saccades & 115.92 \\
\hline 6 & $48, m$ & 4-AP-placebo & $\begin{array}{l}\text { Secondary } \\
\text { (degeneration) }\end{array}$ & 13 & Cerebellar atrophy & 2,5 & -14.60 \\
\hline 7 & $62, \mathrm{~m}$ & 4-AP-placebo & Idiopathic & 1 & Normal & $1,2,3,6$ & -8.13 \\
\hline 8 & $67, \mathrm{~m}$ & 4-AP_placebo & Idiopathic & 2 & Normal & 1,3 & 165.87 \\
\hline 9 & $69, \mathrm{~m}$ & Placebo-4 AP & Idiopathic & 1 & Normal & 2,3 & 5.00 \\
\hline 10 & $62, f$ & 4-AP-placebo & Idiopathic & 4 & Normal & None & 177.08 \\
\hline 11 & $60, f$ & Placebo-4-AP & Idiopathic & 12 & Normal & $2,3,5,6$ & 11.73 \\
\hline 12 & $71, f$ & Placebo-4-AP & Idiopathic & 5 & Normal & $2,3,6$ & 34.10 \\
\hline 13 & $70, \mathrm{~m}$ & Placebo-4-AP & Idiopathic & 11 & Normal & $2,3,6$ & -73.35 \\
\hline 14 & $77, \mathrm{~m}$ & 4-AP_placebo & Idiopathic & 2 & Normal & $1,2,3,4,5$ & -57.19 \\
\hline 15 & $65, m$ & 4-AP_placebo & Idiopathic & 3 & Moderate cerebral atrophy & 3 & \\
\hline 16 & $75, f$ & Placebo-4 AP & Idiopathic & 5 & $\begin{array}{l}\text { White matter lesions } \\
\text { bilaterally and in central } \\
\text { pons }\end{array}$ & 2,3 , hypometric and slowed saccades & -64.62 \\
\hline 17 & $71, \mathrm{~m}$ & 4-AP-placebo & Secondary (SCA-6) & 5 & Normal & 5, slowed saccades & -79.87 \\
\hline 18 & $62, \mathrm{~m}$ & Placebo-4 AP & Idiopathic & 9 & Not possible & 1,3 , hypoactive optokinetic eye movement & 379.00 \\
\hline 19 & $70, f$ & 4-AP-placebo & Idiopathic & 26 & $\begin{array}{l}\text { Marked atrophy of medial } \\
\text { temporal lobe }\end{array}$ & 3 & \\
\hline 20 & $42, f$ & Placebo-4-AP & Idiopathic & 9 & Normal & UBN on upward gaze & -4.04 \\
\hline 21 & $66, m$ & Placebo-4-AP & Idiopathic & 40 & Normal & 2,5 & 33.06 \\
\hline 22 & $23, f$ & Placebo-4-AP & $\begin{array}{l}\text { Secondary } \\
\text { (degeneration) }\end{array}$ & 4 & $\begin{array}{l}\text { Diffuse cerebral, medullar } \\
\text { and cerebellar atrophy }\end{array}$ & 2,5 & 19.99 \\
\hline 23 & $74, f$ & 4-AP_placebo & Idiopathic & 16 & Normal & 5,6 & 90.30 \\
\hline 24 & $74, f$ & 4-AP_placebo & Idiopathic & 5,5 & Normal & $\begin{array}{l}1,3,5,6 \text {, alternating skew deviation during } \\
\text { lateral gaze, gaze holding deficit horizontally and } \\
\text { downward }\end{array}$ & 28.37 \\
\hline 25 & $51, \mathrm{~m}$ & Placebo-4-AP & $\begin{array}{l}\text { Secondary } \\
\text { (paraneoplastic) }\end{array}$ & 3 & $\begin{array}{l}\text { High signals in periphery of } \\
\text { cerebellum bilaterally }\end{array}$ & None & -73.71 \\
\hline 26 & $63, \mathrm{~m}$ & Placebo-4-AP & Idiopathic & 5 & $\begin{array}{l}\text { No path around foramen } \\
\text { magnum, } T 2 \text { hyperintensity } \\
\text { in pons }\end{array}$ & None & 26.88 \\
\hline 27 & $71, \mathrm{~m}$ & 4-AP-placebo & $\begin{array}{l}\text { Secondary } \\
\text { (degeneration) }\end{array}$ & 7,5 & $\begin{array}{l}\text { Various lesions due to } \\
\text { multiple sclerosis }\end{array}$ & Occasionally dysmetric saccades & -98.60 \\
\hline
\end{tabular}

no further indications of structural lesions. ECG and laboratory tests (Vitamin $\mathrm{B} 12$ and $\mathrm{Mg}^{2+}$ ) showed normal results at baseline.

Patients were randomly assigned (for patient flow see figure 1) to receive four single capsules (morning, noon, afternoon and evening) of $5 \mathrm{mg}$ 4-AP (or placebo) for the first 3 days and $10 \mathrm{mg}$ 4-AP (or placebo) for the following 4 days. This was followed by 6 days with no medication (=wash-out period). The treatment was switched (cross-over) 1 week later. All measurements were done before the first drug administration (=baseline), $60 \mathrm{~min}$ after the first drug administration (=5 mg 4-AP or placebo; post 1 ) and $60 \mathrm{~min}$ after the last drug administration (=10 mg 4-AP or placebo; post2) because prior studies in patients with multiple sclerosis had shown that 4-AP is rapidly absorbed, with peak serum levels being reached between $20 \mathrm{~min}$ and $60 \mathrm{~min}$ after dosing. Serum half-life was reported to lie between $1 \mathrm{~h}$ and $3 \mathrm{~h}^{31}$

No patient was taking medication that affected the ocular motor or vestibular systems. In no patient was DBN due to medication or metabolic disorders.

\section{Randomisation and masking}

Patients were randomised (by a computer-generated block randomisation list) to receive first either placebo or 4-AP and then, after the cross-over and wash-out periods, the opposite. The treatment assignments were carried out by providing the clinic with the appropriate treatment kit, which contained the blinded treatments, each in the appropriate order for the patient to whom it was assigned (for further information see online supplementary material no. 1 and figure 1). 
Figure 1 Participant flow. Access the article online to view this figure in colour.

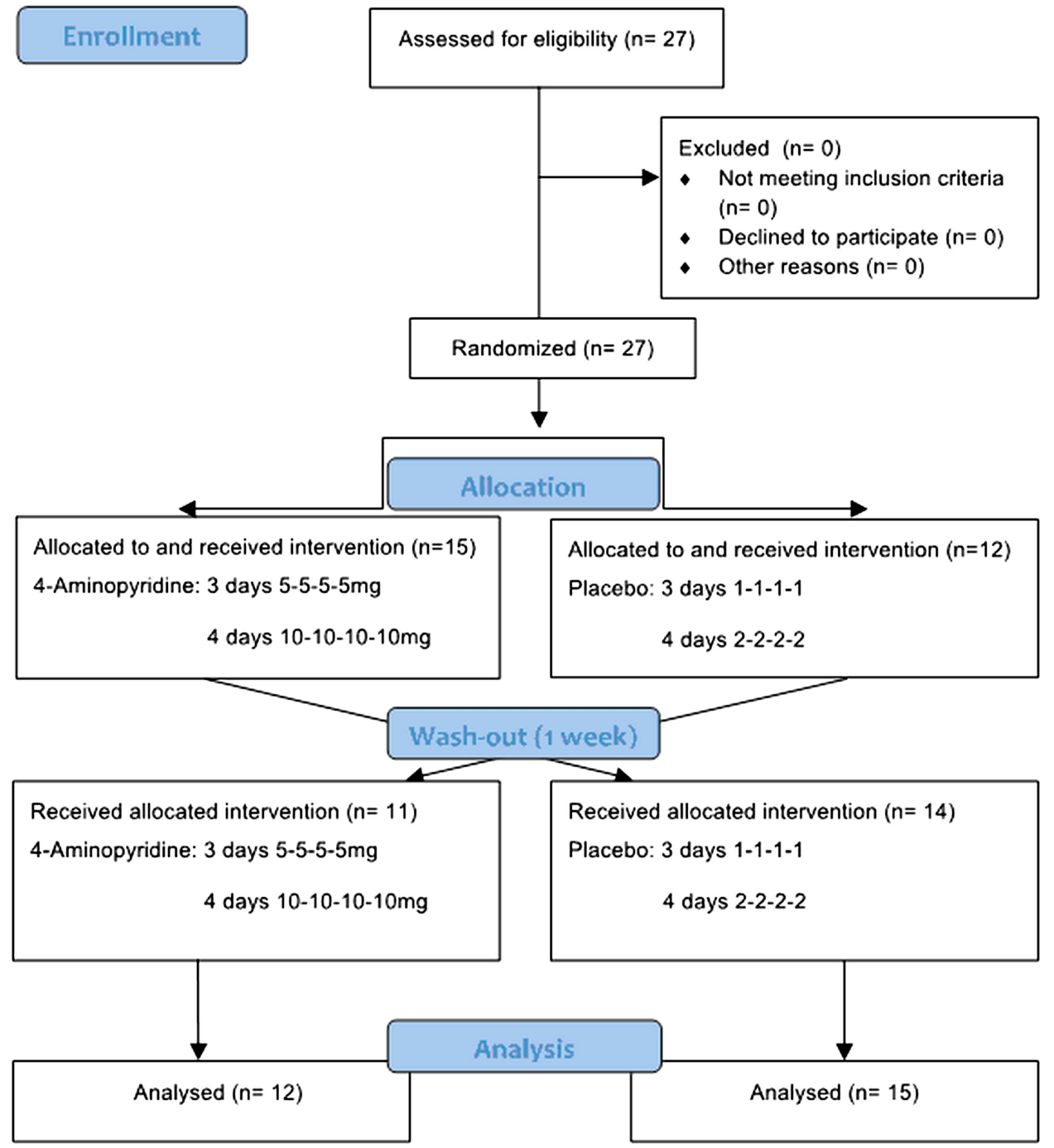

Locomotor tests

Recording of eye movements

Patients were seated in an upright position. Based on prior work, ${ }^{30} 32$ a 30 -second eye movement recording was carried out with 3-D video-oculography (Munich: GN Otometrics Hortmann Vestlab 100; London: Senso-Motoric Instruments Berlin; sampling rate $=50 \mathrm{~Hz}$, resolution $0.1^{\circ}$ in horizontal and vertical direction, accuracy $=0.6^{\circ}$, range $= \pm 30^{\circ}$ in horizontal and vertical directions). The recording order was (1) calibration with targets $8.5^{\circ}$ apart, (2) gaze straight ahead with fixation and (3) gaze straight ahead in darkness. Targets were laser-projected at eye level onto a white cardboard screen located $60 \mathrm{~cm}$ in front of the patient. A padded head restraint was provided. Darkness recordings were for future studies; for the current clinical trial we only report fixation data.

The data analysis was carried out offline using Matlab (The Mathworks, Natick, Massachusetts, USA). The calibrated data were low-pass filtered (for further information see online supplementary material no. 1 ).

\section{Visual acuity}

VA was measured by a Snellen chart with block letters at a distance of $6 \mathrm{~m}$; near VA was measured with the chart at a distance of $30 \mathrm{~cm}$ (optical correction allowed). Measurements were carried out for the left eye and right eye at baseline and after drug/placebo administration. The mean VA of both eyes at each visit was calculated for both distances. Higher values represent better vision.
We used the 'timed get-up-and-go test', a validated tool of clinical gait assessment in elderly patients, fallers and Parkinson's disease. ${ }^{3-36}$ It measures the time (seconds) people take to get up from an armless chair, walk $3 \mathrm{~m}$ away from the chair, turn around and walk back towards the chair and sit down. ${ }^{28}$ Subsequently, the patients performed a tandem walk, ${ }^{29}$ walking for a distance of $2 \mathrm{~m}$; the task was to step onto previously marked areas on the ground. If the person stepped outside these marked areas, this was considered an error (the number of errors was counted at baseline and subsequent to the administration of the drug/placebo). The time (seconds) to complete the task was measured at baseline and after drug/placebo administration.

\section{Posturographic measurements}

Measurements were carried out and postural sway was computed when patients stood upright on firm ground. Total postural-sway values (sway path) for all axes (x,y,z $(\mathrm{m} / \mathrm{min})$ ) were calculated with eyes open and with eyes closed. The mean values of $30 \mathrm{~s}$ on the posturographic measurement device provided an estimation of the mean postural sway (for details see ref ${ }^{37}$ ).

Monitoring of satisfaction and side effects

All patients were given questionnaires (adapted for this study ${ }^{38}$ ) with Likert-scaled items to describe their satisfaction with the 
treatment (drug or placebo). The details of the questionnaire can be found in online supplementary appendix 1 .

\section{Statistical data analysis}

Data were not normally distributed; hence non-parametric statistical tests were carried out (SPSS V.19, IBM Corporation, Somers, New York, USA). To look for differences between baseline and the two different doses of the drug / placebo, Friedman's test with $\chi^{2}$-test statistics was applied. For individual post hoc comparisons, the non-parametric Wilcoxon test statistics were applied with the Bonferroni correction (all two-tailed). The SPV of vertical eye movements was the dependent variable in the eye-movement data. DBN indicated by mean SPV deg/s appears as a positive value on the scale. The time taken (seconds) was the dependent variable in the get-up-and-go test and in the tandem walk. The number of errors represented an additional dependent variable in the tandem-walk task. For posturographic measurements, the average sway values with eyes open/eyes closed represented the dependent variable. In the analysis of VA the dependent variable was the average VA of left eye and right eye for both distances measured. Questionnaire assessment was done by Likert-scaled items (which results in ordinal-scaled data and therefore also requires non-parametric statistical tests). In terms of patient satisfaction with the drug/ placebo, higher values indicate higher levels of satisfaction. On the other hand, higher values on the side effects scale mean that more side effects were experienced. A factor analysis was carried out with the aim of determining which patients benefit most and what patient characteristics may be responsible for treatment response. Non-parametric correlations (Spearman's $\rho$ ) and a partial correlation to control for covariates were subsequently applied to shed light on those patient characteristics that may indicate a better response to treatment.

\section{RESULTS}

\section{Slow phasevelocity}

Mean SPV decreased from a baseline of $2.42 \mathrm{deg} / \mathrm{s} \pm 2.22$ (mean$\pm \mathrm{SD})$ to $1.38 \mathrm{deg} / \mathrm{s} \pm 1.81$ on $5 \mathrm{mg} 4-\mathrm{AP}$ and to $2.03 \mathrm{deg} / \mathrm{s}-$ \pm 2.08 on $10 \mathrm{mg}$ 4-AP. There was an overall decrease of SPV from baseline in the 4-AP group (Friedman's test with $\chi^{2}$-statistics $=6.09, \mathrm{p}<0.05, \mathrm{~N}=23$ ) with a significant post hoc difference between baseline and $5 \mathrm{mg} 4-\mathrm{AP}(\mathrm{p}=0.04)$. This decrease was statistically significant even though all outliers were left in the sample (see figure 2). The post hoc analysis between baseline and $10 \mathrm{mg}$ 4-AP did not reveal a significant decrease of SPV $(\mathrm{p}>0.05)$.

On placebo, mean SPV was $2.02 \mathrm{deg} / \mathrm{s} \pm 2.21$ at baseline, $1.25 \mathrm{deg} / \mathrm{s} \pm 1.89$ at post 1 and $1.76 \mathrm{deg} / \mathrm{s} \pm 2.08$ at post 2 ; there was no significant decrease in terms of SPV (Friedman's test with $\chi^{2}$-statistics $=2.35, \mathrm{p}=0.31, \mathrm{~N}=23$ ). Figure 2 presents the data for placebo along with the data for 4-AP.

Regarding the aetiology of DBN, patients with idiopathic DBN $(\mathrm{N}=21)$ showed an overall significant decrease of SPV on 4-AP (Friedman's test with $\chi^{2}$-statistics $=9.63, \mathrm{p}=0.008, \mathrm{~N}=19$ ) with a significant post hoc difference between baseline and $5 \mathrm{mg}$ 4-AP $(p=0.01)$. On placebo, there was no significant change of SPV $(p>0.05)$. Patients with secondary DBN $(\mathrm{N}=6)$ did not show a significant decrease of DBN (all: $\mathrm{p}>0.05$ ).

\section{Response to treatment}

We calculated the percentage of change of SPV from baseline to the measurement $60 \mathrm{~min}$ after first drug administration for 4-AP and placebo. Afterwards, we subtracted the percentage of change of SPV under placebo from the percentage of change of SPV under 4-AP. Positive values indicated a better response under 4-AP than under placebo and therefore defined as responder. Of the patients, 57\% (13 of 23) were responders (four patients could not be included because of missing values). For an illustration of the change in SPV according to groups of response see figure 3 and table 1.

\section{Visual acuity}

Near VA increased from baseline to the two measurements under 4-AP as follows: baseline: $0.59 \pm 0.31 ; 5 \mathrm{mg}$ 4-AP: $0.66 \pm 0.31 ; 10 \mathrm{mg} 4$-AP: $0.61 \pm 0.29)$. On placebo VA changed from a baseline of $0.59 \pm 0.31$ to $0.63 \pm 0.28$ and $0.61 \pm 0.30$.

Distant VA increased under 4-AP and placebo as follows: 4-AP: baseline: $0.64 \pm 0.26 ; 5 \mathrm{mg}$ : $0.69 \pm 0.26 ; 10 \mathrm{mg}$ : $0.74 \pm 0.27$; placebo: baseline: $0.67 \pm 0.27 ; 0.72 \pm 0.26$ and $0.74 \pm 0.26$.
Figure 2 Box plots showing the median scores and the box-and-whiskers (25/75 percentiles) including outliers prior to 4-API placebo, after $5 \mathrm{mg}$ of 4 -AP/placebo and after $10 \mathrm{mg}$ of $4-A P /$ placebo. The extreme values are represented by the patient numbers in the sample. The differences in terms of mean slowphase velocity (SPV) between baseline and the $5 \mathrm{mg}$ 4-AP condition were significant even when the outliers were included in the dataset. Patient 5 was a 78-year-old woman with a degenerative downbeat nystagmus (DBN) who benefited extremely well from 4-AP in terms of SPV, VA and get-up-and-go test. Patient 25 was a 51 -year-old man with paraneoplastic DBN who did not benefit from 4-AP. Access the article online to view this figure in colour.

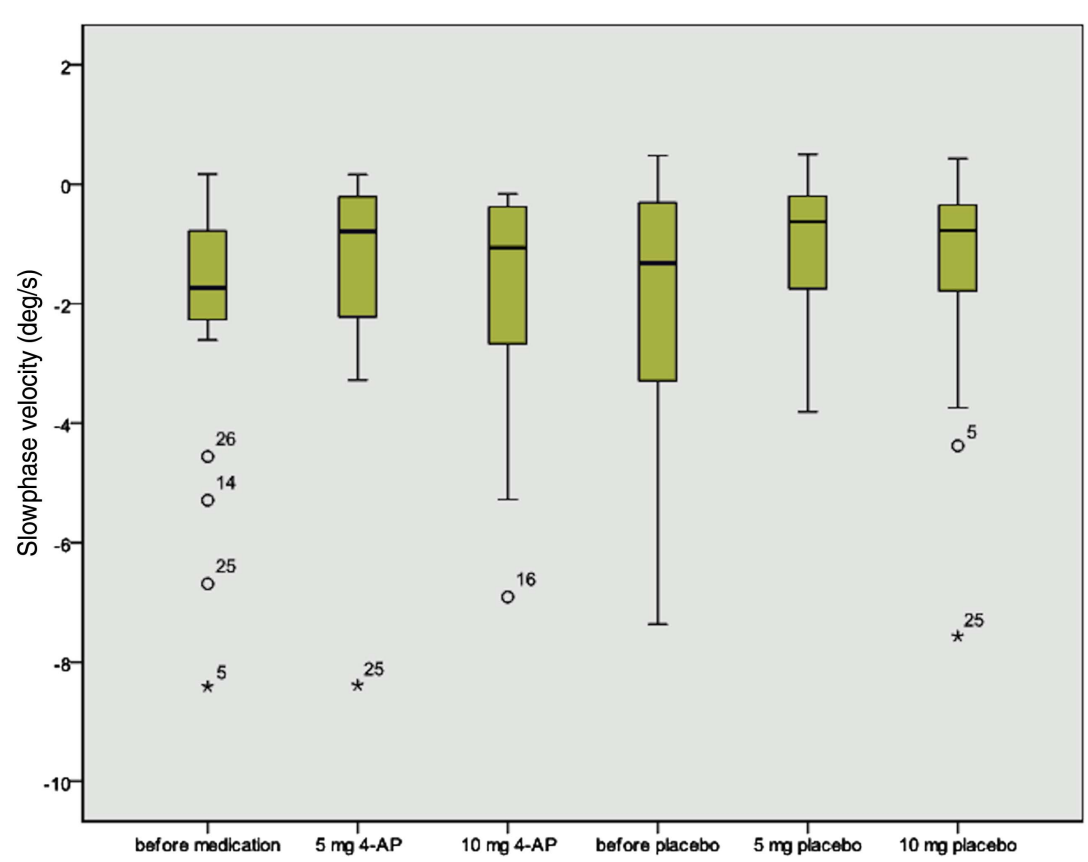


Figure 3 Box plots showing the median scores of slowphase velocity (deg/s) and the box-and-whiskers (25/75 percentiles) including outliers prior to 4-AP/placebo, after $5 \mathrm{mg}$ of 4-AP/placebo and after $10 \mathrm{mg}$ of 4-AP/placebo. Subjects were divided into responders and non-responders.

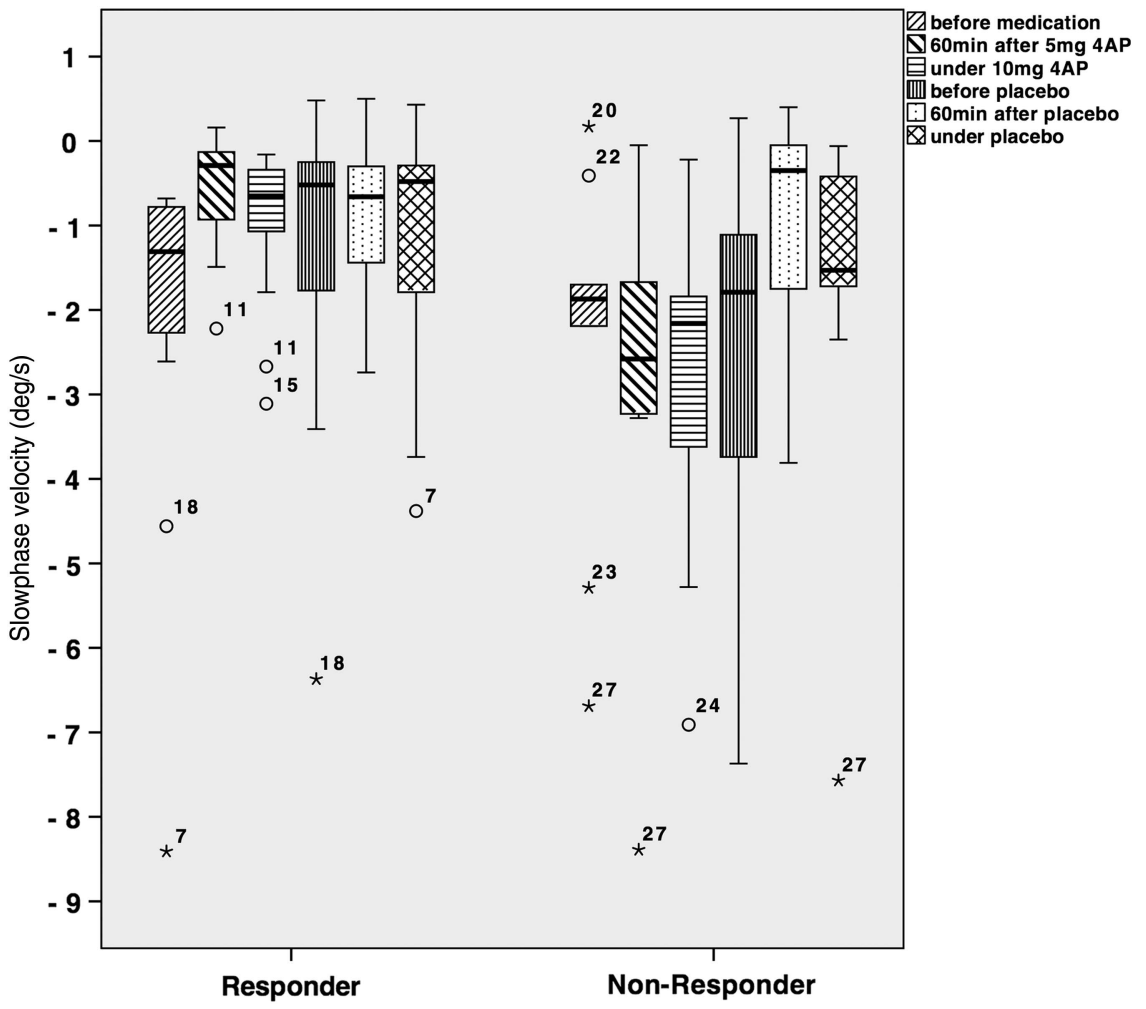

There was an overall increase in near VA from baseline on 4-AP (Friedman's test with $\chi^{2}$-statistics $=6.98, \mathrm{p}<0.05, \mathrm{~N}=23$ ) with a significant post hoc difference between baseline and $5 \mathrm{mg}$ 4-AP $(p=0.01)$. All changes under placebo were not significant $(p>0.05)$. In terms of distant VA, there was also an overall increase from baseline on 4-AP and placebo (Friedman's test with $\chi^{2}$-statistics $=17.79$ and 11.88 , both: $\mathrm{p}<0.05, \mathrm{~N}=24$ ) with a significant post hoc difference between baseline and $5 \mathrm{mg}$ 4-AP and between baseline and $10 \mathrm{mg}$ 4-AP (all: $\mathrm{p}<0.05$ ). In the placebo group, there was also a significant post hoc difference between baseline and the first and second measurements after administration (all: $\mathrm{p}<0.05$ ).

\section{Locomotion tasks}

The 'get-up-and-go test' revealed a reduction of time (in seconds) from $12.27 \pm 13.58$ at baseline to $12.15 \pm 17.22$ on $5 \mathrm{mg}$ 4-AP and 9.4 \pm 7.19 on $10 \mathrm{mg}$ 4-AP (Friedman's test with $\chi^{2}$-statistics $\left.=18.11, \mathrm{p}<0.001\right)$; significant post hoc difference between baseline and $5 \mathrm{mg}$ 4-AP $(\mathrm{p}=0.025)$ and between baseline and $10 \mathrm{mg} 4-\mathrm{AP}(\mathrm{p}<0.001)$. The placebo condition did not have a significant effect on this task (Friedman's test with $\chi^{2}$-statistics $=4.625, p=0.1$ ). On placebo the time (in seconds) changed from $13.12 \pm 15.24$ at baseline to $11.44 \pm 11.85$ and $12.14 \pm 16.32$.

With regard to the aetiology of DBN, patients with idiopathic DBN showed an overall improvement on 4-AP (Friedman's test with $\chi^{2}$-statistics $=12.94, \mathrm{p}=0.002, \mathrm{~N}=18$ ) with a significant post hoc difference between baseline and $5 \mathrm{mg} 4-\mathrm{AP}(\mathrm{p}=0.018)$ and baseline and $10 \mathrm{mg} 4-\mathrm{AP}, \mathrm{p}=0.002$ ). In the group of patients with DBN caused by degeneration, there was only a marginally significant overall improvement on 4-AP (Friedman's test with $\chi^{2}$-statistics $=5.73, \mathrm{p}=0.057, \mathrm{~N}=5$ ). On placebo, no significant changes were found.

Tandem-walk time improved in patients administered 4-AP (baseline: $6.62 \mathrm{~s} \pm 5.12 ; 5 \mathrm{mg}: 6.28 \mathrm{~s} \pm 4.85 ; 10 \mathrm{mg}: 5.17 \mathrm{~s}$ \pm 3.55 ; Friedman's test with $\chi^{2}$-statistics $=11.085, \mathrm{p}<0.01$,
$\mathrm{N}=22$ ), and in patients given placebo (baseline: $7.66 \mathrm{~s} \pm 5.34$; after $60 \mathrm{~min}: 6.11 \mathrm{~s} \pm 5.54$; after 1 week: $6.22 \mathrm{~s} \pm 7.33$;

Tandem-walk error improved on 4-AP (baseline: $1.83 \pm 2.19$; $5 \mathrm{mg}$ 4-AP: $1.70 \pm 1.84 ; 10 \mathrm{mg} 4-\mathrm{AP}: 1.22 \pm 1.60)$ and placebo (baseline: $1.63 \pm 1.97 ; 5 \mathrm{mg}$ : $1.21 \pm 2.02 ; 10 \mathrm{mg}$ : $1.36 \pm 1.92$ ) for 4-AP: Friedman's test with $\chi^{2}$-statistics $=5.85, \mathrm{p}=0.054$, $\mathrm{N}=21$, for placebo: Friedman's test with $\chi^{2}$-statistics $=5.67$, $\mathrm{p}=0.059, \mathrm{~N}=22$ ).

\section{Posturography}

In the placebo condition, postural stability remained unchanged with the eyes open (baseline: $1.64 \mathrm{~m} / \mathrm{min} \pm 0.78$; after $60 \mathrm{~min}$ : $1.68 \mathrm{~m} / \mathrm{min} \pm 0.91$; after 1 week: $1.71 \mathrm{~m} / \mathrm{min} \pm 0.58)$ and eyes closed (baseline: $3.65 \mathrm{~m} / \mathrm{min} \pm 4.35$; post 1 : $3.38 \mathrm{~m} / \mathrm{min} \pm 4.71$; post $2: 3.47 \mathrm{~m} / \mathrm{min} \pm 3.73$ ). Postural stability with eyes open worsened from $1.51 \mathrm{~m} / \mathrm{min} \pm 0.82$ at baseline to $1.71 \mathrm{~m} / \mathrm{min} \pm 0.78$ on $5 \mathrm{mg}$ and $2.05 \mathrm{~m} / \mathrm{min} \pm 1.36$ on $10 \mathrm{mg} \mathrm{4-AP}$. Under the condition eyes-closed, it changed from $2.92 \mathrm{~m} / \mathrm{min} \pm 3.44$ at baseline to $3.14 \mathrm{~m} / \mathrm{min} \pm 3.34$ on $5 \mathrm{mg} 4-\mathrm{AP}$ and $3.60 \mathrm{~m} / \mathrm{min} \pm 4.01$ on $10 \mathrm{mg}$ 4-AP.

The overall change in postural stability was significant on 4-AP (eyes open: Friedman's test with $\chi^{2}$-statistics $=7.18$, $\mathrm{p}<0.05, \quad \mathrm{~N}=22$, eyes closed: Friedman's test with $\chi^{2}$-statistics $=9.24, \mathrm{p}=0.01, \mathrm{~N}=21$ ). Post hoc tests revealed that patients were significantly less stable on $10 \mathrm{mg}$ 4-AP (eyes open: $p=0.017$, eyes closed: $p=0.002$ ), whereas no significant post hoc tests were found after the administration of $5 \mathrm{mg} 4-\mathrm{AP}$ (eyes open: $p=0.12$, eyes closed: $p=0.35$ ).

Postural stability did not generally decrease with 4-AP. The opposite was found for increasing age with the $5 \mathrm{mg}$ 4-AP dose: it caused increasing postural stability when patients had their eyes closed. Using age as a covariate, increasing age correlated significantly with the 4-AP-related decrease in SPV in the $5 \mathrm{mg}$ group ( partial correlation $=0.54, p<0.05$, see figure 4 ). Friedman's test with $\chi^{2}$-statistics $=11.028, \mathrm{p}<0.01, \mathrm{~N}=22$ ). 
Figure 4 The association of age (in years) and improvement with $5 \mathrm{mg}$ 4 -AP in terms of mean slow-phase velocity (SPV) relative to baseline mean SPV measurements. The positive correlation between both variables was statistically significant.

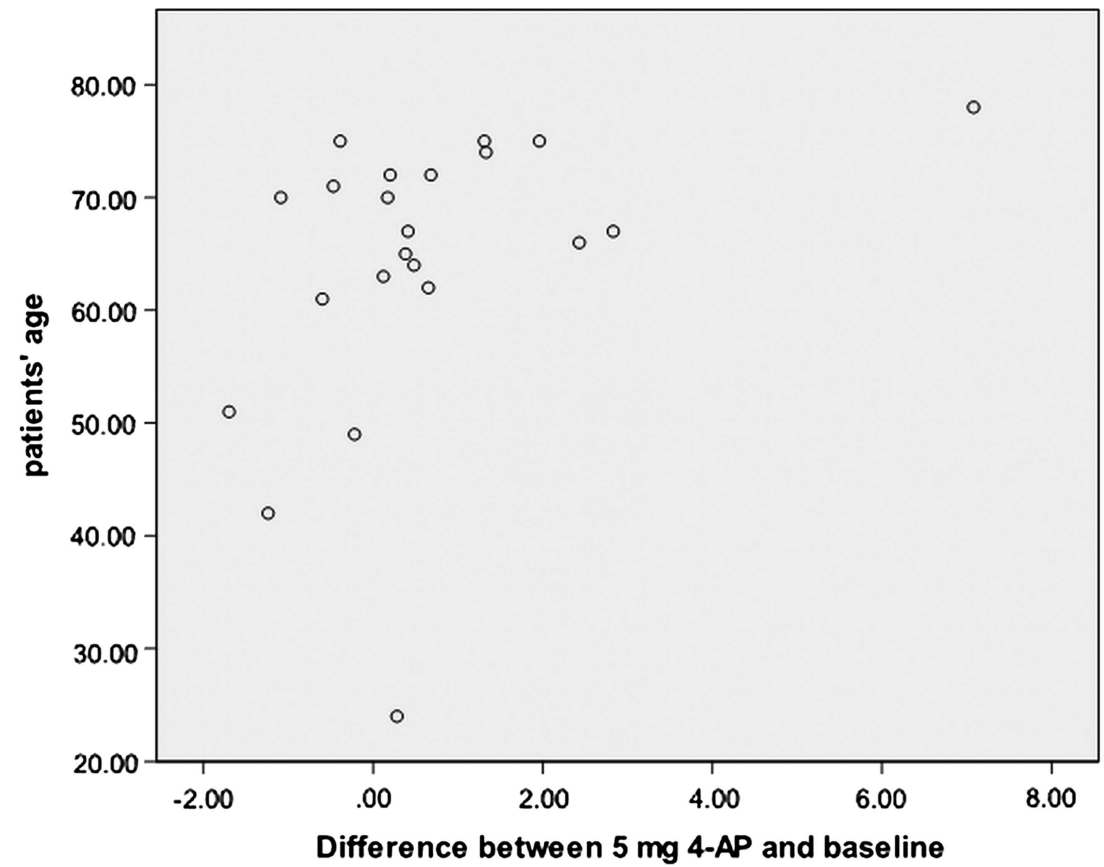

\section{Side effects and patient satisfaction}

Reported side effects were nausea (four patients on active substance, two on placebo, one on both), vomiting (three on active substance), sleep disturbances (three on active substance, one on placebo), sleepiness (one on active substance, one on placebo), paraesthesias (one on active substance, one on placebo), palpitations (one on placebo, one on both), worsened balance (two on active substance) and blurred vision (one on active substance). One patient was removed from the study because of a prolonged QTc time (QT time in electrocardiography corrected for heart rate) on 4-AP; one patient dropped out of the study because symptoms continued on placebo.

In terms of patient satisfaction, patients were able to choose between the options very happy (ie, want to stay on the drug, 3 points), happy (ie, some benefit, 2 points), not at all happy (want to stop, one point). Patient satisfaction was similar for 4-AP $(2.23 \pm 0.92)$ and placebo $(2.55 \pm 0.51)$ (Wilcoxon signed rank test $\mathrm{p}>0.2)$. The frequency of side effects also did not differ between groups (Wilcoxon signed rank test $\mathrm{p}>0.08$ ). Improvement of DBN, VA and/or postural stability did not have a significant influence on patient satisfaction or on reported side effects (partial correlation: $\mathrm{p}>0.05$ ).

\section{DISCUSSION}

It is well established that aminopyridines decrease the intensity of DBN. ${ }^{318} 2039{ }^{40}$ Furthermore, 4-AP is evidently more effective than 3,4-diaminopyridine ${ }^{31} 36-3841$ because it crosses the blood-brain barrier more easily. ${ }^{42} 43$

In the current study 4-AP significantly reduced the SPV of DBN but only during treatment with $5 \mathrm{mg}$. Of the patients $57 \%$ responded to 4-AP. The SD with $10 \mathrm{mg}$ was higher than with $5 \mathrm{mg}$ which may explain why the difference was not statistically significant. The underlying mechanism of this unexpected dose-effect is so far unclear.

The reduction was less pronounced than that reported in previous studies. $^{3} 5$ 18-20 42 However, the variation of SPV was high at baseline and there were also a number of outliers in the dataset. All outliers were, however, left in, in order to represent all patients, including those with extreme findings. It is worth noting that excluding the outliers would have enhanced the beneficial effects of 4-AP given that the outliers showed poor response to the active drug, which may depend on the aetiology of DBN (see below). Examining the overall response rate, which was higher on 4-AP than on placebo, we can conclude that even though not all patients in our sample responded to the drug, the general finding of previous studies was confirmed. Therefore we also tried to identify those patients who were more likely to respond to the drug, a practical clinical point. It turned out that increasing age predicted better DBN response to 4-AP. Age was also associated with increased postural stability with closed eyes and the $5 \mathrm{mg}$ dose. Further, patients with idiopathic DBN benefited most in terms of SPV (as in a previous study ${ }^{3}$ ) and the get-up-and-go test.

Near VA improved significantly on $5 \mathrm{mg}$ 4-AP. The decreased SPV of DBN with $5 \mathrm{mg}$ 4-AP might have led to a better VA. Distant VA improved on 4-AP and placebo. Values of distant VA were generally higher than those of near VA. This can be explained by the age of the patients and the higher incidence of presbyopia $^{44}$ or because convergence usually increases the intensity of DBN. Yee et $a l^{45}$ reported an enhancement of DBN at convergence in $64 \%$ of the tested patients, perhaps giving more chances for the 4-AP to work.

In terms of locomotion, 4-AP significantly improved performance in the 'get-up-and-go test'. The improved performance over baseline levels in the tandem-walk time and the tandem-walk error tests, however, cannot be interpreted as a result of 4-AP, as these improvements were also seen in the placebo condition.

Postural sway increased on 4-AP, whereas no difference was found for placebo. Especially higher doses of 4-AP led to increased postural sway in the eyes-open and eyes-closed conditions, whereas lower doses did not show a significant effect. These findings suggest that there could be a dissociation between the vestibulo-ocular and vestibulospinal systems in their dose responsiveness to 4-AP. All other parameters of locomotion and balance tested did not show any significant correlation to SPV. Regarding postural stability, it should also be mentioned that many patients did not have high postural sway values at 
baseline, especially at eyes-open condition. In the group of older patients $5 \mathrm{mg}$ 4-AP improved postural stability perhaps due to the increased sway at baseline especially the eyes-closed condition and therefore worse capacity of postural stability at the beginning. However, this does not necessarily imply that 4-AP is deleterious to postural stability, since increasing age was associated with improved postural stability due to 4-AP (in the $5 \mathrm{mg}$ dose only). These findings, together with the locomotor findings, warrant further investigation.

Only a few side effects were reported in the course of the study, in particular nausea, paraesthesia and sleep disturbances. There were, however, no differences in the total frequency of side effects between 4-AP and placebo; this indicates that overall 4-AP is well tolerated. Patient satisfaction was similar on 4-AP and placebo. Given that 4-AP is a drug for symptomatic but not causative treatment, one would expect to see higher patient satisfaction scores among those patients receiving the drug than among those patients receiving placebo, so why did we not see any relevant differences in terms of patient satisfaction? While 4-AP decreases the amount of DBN, it certainly does not make DBN vanish completely. The fact that DBN just about improves on $5 \mathrm{mg}$ 4-AP (but not on $10 \mathrm{mg}$ 4-AP), while there is a slight (but not statistically significant) improvement in the placebo condition, would suggest that the positive effects of 4-AP might have gone unnoticed for a substantial number of patients. This could be a reason for the absence of statistically significant differences in the patient satisfaction scales. It should be mentioned that the questionnaire was not validated for patients with cerebellar disease. Therefore, longer trials with more detailed and validated questionnaires involving $5 \mathrm{mg} 4$-AP or $10 \mathrm{mg}$ of the sustained-release form may yield higher scores in terms of patient satisfaction.

From a clinical point of view, this study shows that 4-AP is a promising medication for patients with DBN. It leads to a significant DBN reduction following the $5 \mathrm{mg}$ dose. According to our results, the $5 \mathrm{mg}$ four times a day dose seems to have better effects on the mean SPV data and the VA measurements, it is not generally associated with decreased postural stability and it was associated with improved postural stability in elderly patients. Especially older people who are at risk of stumbling should therefore be tested thoroughly before higher doses of 4-AP are given.

There is a heterogeneous response rate among patients, with some experiencing great benefits, and others worsening, but patients with idiopathic DBN seem to have greater benefit. ${ }^{3} 20$ In regular clinical visits it should be decided on a case-by-case basis if a patient benefits from treatment or not. If eye recording is performed to support this decision it is important that the measurements are done in the same position and at the same time of day at each visit. ${ }^{30} 32$

In future studies, it will be important to look for patterns that might explain why some patients respond to 4-AP while others do not. One possible starting point for further studies in terms of pathophysiology may be the investigation of a possible dose effect of 4-AP on the brain areas (eg, deep cerebellar or vestibular nuclei) involved in DBN.

From a pharmacological perspective, it may also be worth administering the sustained released form of 4-AP (Ampyra, Biogen Idec, Cambridge, Massachusetts, USA or Fampyra, Europe), since it may have longer-lasting effects and fewer side effects and contraindications. Future studies will be needed to clarify these aspects.

Acknowledgements The authors thank all patients for taking part in our study. We thank Katie Ogston and Judy Benson for copy-editing this manuscript and Dr Stefan Glasauer for his technical support.
Contributors JC and RS: substantial contributions to acquisition of data, analysis and interpretation of data; drafting the article and revising it critically for important intellectual content; and final approval of the version to be published. The statistical analysis was carried out by RS. RK: substantial contributions to conception and design, acquisition of data and analysis and interpretation of data; revising the article critically for important intellectual content; and final approval of the version to be published. MF: substantial contributions to conception and design and acquisition of data; final approval of the version to be published. CK: substantial contributions to conception and design; final approval of the version to be published. CD: substantial contributions to conception, design and acquisition of data; SB, NR, ES, TB and KJ: substantial contributions to analysis and interpretation of data; revising the article critically for important intellectual content; and final approval of the version to be published. JT: substantial contributions to analysis and interpretation of data; drafting the article and revising it critically for important intellectual content; and final approval of the version to be published. MS and AB: substantial contributions to conception and design, acquisition of data and analysis and interpretation of data; drafting the article and revising it critically for important intellectual content; and final approval of the version to be published.

Funding This work was supported by the German Ministry of Education and Research (BMBF), Grant No. 01 E00901 to the German Center for Vertigo and Balance Disorders (IFBLMU) and by the UK Medical Research Council.

\section{Competing interests None.}

\section{Patient consent Obtained.}

Ethics approval All patients gave their informed consent to participate in our study, which was performed in line with the Helsinki II Declaration and approved by the Ethics Committees of Ludwig-Maximilians University of Munich, Germany and Imperial College London, UK.

Provenance and peer review Not commissioned; externally peer reviewed.

\section{REFERENCES}

1 Baloh RW, Spooner JW. Downbeat nystagmus: a type of central vestibular nystagmus. Neurology 1981;31:304-10.

2 Bronstein AM. Vision and vertigo: some visual aspects of vestibular disorders. J Neurol 2004;251:381-7.

3 Kalla R, Glasauer S, Buttner U, et al. 4-aminopyridine restores vertical and horizontal neural integrator function in downbeat nystagmus. Brain 2007;130:2441-51.

4 Leigh RJ. Potassium channels, the cerebellum, and treatment for downbeat nystagmus. Neurology 2003;61:158-9.

5 Helmchen C, Sprenger A, Rambold H, et al. Effect of 3,4-diaminopyridine on the gravity dependence of ocular drift in downbeat nystagmus. Neurology 2004:63:752-3.

6 Pierrot-Deseilligny C, Milea D. Vertical nystagmus: clinical facts and hypotheses. Brain 2005:128:1237-46.

7 Hufner K, Stephan T, Kalla R, et al. Structural and functional MRIs disclose cerebellar pathologies in idiopathic downbeat nystagmus. Neurology 2007;69:1128-35.

8 Wagner JN, Glaser M, Brandt T, et al. Downbeat nystagmus: aetiology and comorbidity in 117 patients. I Neurol Neurosurg Psychiatry 2008;79:672-7.

9 Zee DS, Yamazaki A, Butler PH, et al. Effects of ablation of flocculus and paraflocculus of eye movements in primate. J Neurophysiol 1981;46:878-99.

10 Kalla R, Deutschlander A, Hufner K, et al. Detection of floccular hypometabolism in downbeat nystagmus by fMRI. Neurology 2006;66:281-3.

11 Glasauer S, Strupp M, Kalla R, et al. Effect of 4-aminopyridine on upbeat and downbeat nystagmus elucidates the mechanism of downbeat nystagmus. Ann N Y Acad Sci 2005; 1039:528-31.

12 Marti S, Straumann D, Buttner U, et al. A model-based theory on the origin of downbeat nystagmus. Exp Brain Res 2008;188:613-31.

13 Giovannini F, Sher E, Webster R, et al. Calcium channel subtypes contributing to acetylcholine release from normal, 4-aminopyridine-treated and myasthenic syndrome auto-antibodies-affected neuromuscular junctions. Br J Pharmacol 2002;136:1135-45.

14 Goodman AD, Brown TR, Cohen JA, et al. Dose comparison trial of sustained-release fampridine in multiple sclerosis. Neurology 2008;71:1134-41.

15 Hauser SL, Johnston SC. 4-aminopyridine: new life for an old drug. Ann Neurol 2010;68:A8-9.

16 Oh SJ, Claussen GG, Hatanaka Y, et al. 3,4-Diaminopyridine is more effective than placebo in a randomized, double-blind, cross-over drug study in LEMS. Muscle Nerve 2009:40:795-800

17 Quartel A, Turbeville S, Lounsbury D. Current therapy for Lambert-Eaton myasthenic syndrome: development of 3,4-diaminopyridine phosphate salt as first-line symptomatic treatment. Curr Med Res Opin 2010;26:1363-75.

18 Kalla R, Glasauer $S$, Schautzer F, et al. 4-aminopyridine improves downbeat nystagmus, smooth pursuit, and VOR gain. Neurology 2004;62:1228-9.

19 Sprenger A, Rambold H, Sander T, et al. Treatment of the gravity dependence of downbeat nystagmus with 3,4-diaminopyridine. Neurology 2006;67:905-7. 
20 Strupp M, Schuler O, Krafczyk S, et al. Treatment of downbeat nystagmus with 3,4-diaminopyridine: a placebo-controlled study. Neurology 2003;61:165-70.

21 Strupp M, Kalla R, Claassen J, et al. A randomized trial of 4-aminopyridine in EA2 and related familial episodic ataxias. Neurology 2011;77:269-75.

22 Strupp M, Kalla R, Dichgans M, et al. Treatment of episodic ataxia type 2 with the potassium channel blocker 4-aminopyridine. Neurology 2004;62:1623-5.

23 Lohle $\mathrm{M}$, Schrempf $\mathrm{W}$, Wolz $\mathrm{M}$, et al. Potassium channel blocker 4-aminopyridine is effective in interictal cerebellar symptoms in episodic ataxia type 2-a video case report. Mov Disord 2008;23:1314-16.

24 Schniepp R, Wuehr M, Ackl N, et al. 4-aminopyridine improves gait variability in cerebellar ataxia due to CACNA 1A mutation. J Neurol 2011;258:1708-11.

25 Alvina K, Khodakhah K. The therapeutic mode of action of 4-aminopyridine in cerebellar ataxia. J Neurosci 2010;30:7258-68.

26 Alvina K, Khodakhah K. KCa channels as therapeutic targets in episodic ataxia type-2. J Neurosci 2010;30:7249-57.

27 Etzion Y, Grossman Y. Highly 4-aminopyridine sensitive delayed rectifier current modulates the excitability of guinea pig cerebellar Purkinje cells. Exp Brain Res 2001;139:419-25.

28 Podsiadlo D, Richardson S. The timed "Up \& Go": a test of basic functional mobility for frail elderly persons. J Am Geriatr Soc 1991;39:142-8.

29 Cho BL, Scarpace D, Alexander NB. Tests of stepping as indicators of mobility, balance, and fall risk in balance-impaired older adults. J Am Geriatr Soc 2004;52:1168-73.

30 Spiegel $R$, Rettinger $N$, Kalla $R$, et al. The intensity of downbeat nystagmus during daytime. Ann N Y Acad Sci 2009;1164:293-9.

31 Judge SI, Bever CT Jr. Potassium channel blockers in multiple sclerosis: neuronal $\mathrm{KV}$ channels and effects of symptomatic treatment. Pharmacol Ther 2006;111:224-59.

32 Spiegel R, Kalla R, Rettinger N, et al. Head position during resting modifies spontaneous daytime decrease of downbeat nystagmus. Neurology 2010:75:1928-32
33 Bronstein AM, Pavlou M. Balance. Handb Clin Neurol 2013;110:189-208.

34 Lim I, van Wegen E, Jones $D$, et al. Identifying fallers with Parkinson's disease using home-based tests: who is at risk? Mov Disord 2008;23:2411-15.

35 Macleod AD, Counsell CE. Timed tests of motor function in Parkinson's disease. Parkinsonism Relat Disord 2010;16:442-6.

36 Wall JC, Bell C, Campbell S, et al. The Timed Get-up-and-Go test revisited: measurement of the component tasks. J Rehabil Res Dev 2000:37:109-13.

37 Krafczyk S, Tietze S, Swoboda W, et al. Artificial neural network: a new diagnostic posturographic tool for disorders of stance. Clin Neurophysiol 2006;117: 1692-8.

38 Grunfeld EA, Morland AB, Bronstein AM, et al. Adaptation to oscillopsia: a psychophysical and questionnaire investigation. Brain 2000;123(Pt 2):277-90.

39 Kalla R, Spiegel R, Wagner J, et al. Pharmacotherapy of central oculomotor disorders. Nervenarzt 2008;79:1377-8, 1380-1372, 1384-1375.

40 Sprenger A, Zils E, Rambold H, et al. Effect of 3,4-diaminopyridine on the postural control in patients with downbeat nystagmus. Ann N Y Acad Sci 2005; 1039:395-403.

41 Kalla R, Spiegel R, Claassen J, et al. Comparison of 10-mg doses of 4-aminopyridine and 3,4-diaminopyridine for the treatment of downbeat nystagmus. J Neuroophthalmol 2011;31:320-5.

42 Hayes KC, Katz MA, Devane JG, et al. Pharmacokinetics of an immediate-release oral formulation of Fampridine (4-aminopyridine) in normal subjects and patients with spinal cord injury. J Clin Pharmacol 2003:43:379-85.

43 Lemeignan M, Millart $\mathrm{H}$, Lamiable $\mathrm{D}$, et al. Evaluation of 4-aminopyridine and 3,4-diaminopyridine penetrability into cerebrospinal fluid in anesthetized rats. Brain Res 1984;304:166-9.

44 Loh KY, Ogle J. Age related visual impairment in the elderly. Med J Malaysia 2004;59:562-8, quiz 569.

45 Yee RD. Downbeat nystagmus characteristics and localization of lesions. Trans Am Ophthalmol Soc 1989;87:984-1032. 

of 4-aminopyridine for downbeat nystagmus --effects on slowphase eye velocity, postural stability, locomotion and symptoms

Jens Claassen, Rainer Spiegel, Roger Kalla, Mary Faldon, Christopher Kennard, Chotipat Danchaivijitr, Stanislaw Bardins, Nicole Rettinger, Erich Schneider, Thomas Brandt, Klaus Jahn, Julian Teufel, Michael Strupp and Adolfo Bronstein

J Neurol Neurosurg Psychiatry 2013 84: 1392-1399 originally published online June 29, 2013

doi: 10.1136/jnnp-2012-304736

Updated information and services can be found at:

http://jnnp.bmj.com/content/84/12/1392

\section{Supplementary Material}

References

Email alerting service

\section{These include:}

Supplementary material can be found at:

http://jnnp.bmj.com/content/suppl/2013/06/30/jnnp-2012-304736.DC1. html

This article cites 45 articles, 7 of which you can access for free at: http://jnnp.bmj.com/content/84/12/1392\#BIBL

Receive free email alerts when new articles cite this article. Sign up in the box at the top right corner of the online article.

Topic Articles on similar topics can be found in the following collections Collections Ophthalmology (759)

\section{Notes}

To request permissions go to:

http://group.bmj.com/group/rights-licensing/permissions

To order reprints go to:

http://journals.bmj.com/cgi/reprintform

To subscribe to BMJ go to:

http://group.bmj.com/subscribe/ 